schizophrenic offspring in their cohort to be capable of refuting hypothesis (b); and if contracting influenza in mid-pregnancy does indeed double the child's risk of developing schizophrenia, that would surely be important both to our understanding of schizophrenia and as a public health issue.

Adams, W. Kendell, R. E. (19960) Influenza and schizophrenia (letter). British Journal of Psychiotry, 169. 252-253.

- - (19966) Influenza and schizophrenia (letter). British Journal of Psychiotry, 169, 791-792.

W. Adams, R. E. Kendell University of Edinburgh Medical School, Edinburgh EH8 9AF

\section{Early detection of schizophrenia}

Sir: The detection of pre-schizophrenia using "at risk mental states" (Birchwood et al, 1997) is crucially dependent on (a) the prevalence of the hypothesised 'pre-clinical' schizophrenia disease state, and (b) the specificity and positive predictive value (PPV) of the risk indicator. Pre-clinical schizophrenia is, by definition, a state of transition, and its prevalence in the population will therefore approach (low) schizophrenia incidence. The specificity of detection criteria such as ideas of reference is also low, because these symptoms are much more prevalent in the general population than is pre-schizophrenia (e.g. Eaton et al, 1991). Let us assume that (a) as many as $50 \%$ of pre-schizophrenics have easily detectable ideas of reference; (b) the pre-clinical disease state has a prevalence of $0.05 \%$ in the population; and (c) the specificity of ideas of reference is as high as $\mathbf{9 0 \%}$. Even these values will yield an unworkably low PPV of $0.3 \%$ (of 1000 having 'at risk' mental states, only three have disease).

Combining criteria (Birchwood et al, 1997) in a parallel fashion will further decrease the already low PPV, and although serial combination of criteria may increase the specificity somewhat, the number of undetected cases will increase with each serial step, so that eventually one is left with an insignificant proportion of the cases that one had set out to detect (Hennekens \& Buring, 1987).

McGorry's group also used trait indicators of risk, such as family history, claiming high schizophrenia transition rates in groups with serially combined state and trait indicators (Yung et al, 1996). However, most cases had already been referred to a psychosis service before 'transition', and individuals without state/trait indicators were not followed-up for their transition rate (thus making it impossible to establish the PPV of the detection criteria). In addition, application of categorical decision rules (case/noncase) on dimensional scale structures (subcase) is confusing, and subject to a statistical 'transition' artifact similar to the one that generates regression to the mean. Only $20 \%$ of schizophrenics have a first-degree relative with the same diagnosis (low sensitivity), and only $10 \%$ of first-degree relatives of schizophrenics will develop the disease (low specificity), resulting in a very low PPV if the possibility of early detection in non-selected populations is examined.

Birchmood, M., McGorry, P. \& Jeckson, H. (1997) Early intervention in schizophrenia. British Journal of Psychiotry, 170. 2-5.

Eaton, W. W., Romanowski, A., Anthomy, J., et al (1991) Screening for psychosis in the general population with a selfreport interview. Journal of Nervous and Mentol Diseose. 179. 689-693.

Hennekens, C. \& Buring, J. (1987) Epidemiology in Medicine. pp. 334-335. Boston, MA: Little Brown \& Company.

Yung, A. R., McGorry, P. D., MeFartane, C. A., of al (1996) Monitoring and care of young people at incipient risk of psychosis. Schizophrenia Bulletin, 22, 283-305.

J. van Os University of Maastricht, PO Box 616. 6200 MD Maastricht, The Netherlands

N. Takei Institute of Psychiatry, London

H. Verdoux University of Bordeaux II, Bordeaux, France

P. Delespaul University of Maastricht, Maastricht, The Netherlands

\section{Terminology of learning disability}

Sir: I agree wholeheartedly with Reid (1997) that the term 'learning disability' is confusing. This is a particular problem among professionals working with children. Some use the term of children with mental retardation, some use the term of children with normal intelligence who have specific development disorders of scholastic skills, while others use it to describe children who are failing to achieve their academic potential whatever the reason. It is important that we all use a clear diagnostic term, whatever this is to be. It is also important that this diagnostic term is decided upon by doctors and not by politicians. My preference is for the term 'mental retardation', which is used in both ICD-10 and DSM-IV.

Reid, A. H. (1997) Mental handicap or learning disability. A critique of political correctness. British Journal of Psychiotry. 170. I.

R. Davey The Hawthorn Centre Child and Adolescent Mental Health Service, Commerce House, Dene Drive, Winsford, Cheshire CW7 IAS
Sir: Reid (1997) suggests that rejecting old labels may be about denying the very existence of difference and may thus allow denial and dismissal of need. I agree that this can be an unhealthy part of the dismissal of labels but examining our labels for difference is ultimately about a healthy and maturing dynamic in society.

It is interesting that Reid describes awareness in labelling starting with race, then gender, then disability. I feel this is an evolution in society. Why did we have race and gender discrimination acts in the 1970s with strong powers of enforcement but no disability discrimination act until the 1990s and with only weak enforcement powers? In the fight for racial de-segregation in schools, minorities were often told it was better for them to be placed in segregated schools where their needs were understood - an argument that would be seen as outrageous today. Within contemporary families such arguments are often used to deny their 'different' child with disability a place in a mainstream school.

Reid criticises the term learning disability as containing no suggestion of medicine. Surely this is an example of the arrogance for which the medical profession is criticised. People living with the difference of learning difficulties would perhaps reject terms which define them as a medical grouping rather than as different but true members of our community.

The words 'learning disability' are not perfect, but debate about this can only be healthy. I would suggest that an even more important issue is that attitude and provision are even less perfect and that challenging our labels helps us grapple with these very issues.

Redd, A. H. (1997) Mental handicap or learning disability. A critique of political correctness. British fournal of Psychiotry, I70. 1.

M. F. Bowden Tindal Centre, Bierton Road, Aylesbury, Buckinghamshire HP20 IHU

\section{Confidential Inquiry Into Suicide and Homicide by Mentally III People}

Sir: The Confidential Inquiry into Suicide and Homicide by People with Mental Illness now enters a new stage (Appleby et al, 1997). Much emphasis will now be placed upon establishing a complete and representative sample of all relevant suicides, identified through data obtained from local Directors of Public Health, to whom HM coroners routinely notify inquest verdicts. 
I was a member of the first Inquiry Steering Group, which encouraged clinicians themselves to notify suicides to the Inquiry. As I understand the approach to be adopted in the next stage, local clinical review for the Inquiry's purpose will inevitably be significantly delayed in a considerable proportion of suicides, as a result of first having to await inquest verdicts in order to establish a full sample of patients. I fear that other problems will then arise, because we have found in Avon that any such delay may severely compromise the collection of full reliable data relevant to clinical audit. Under present clinical conditions, high-risk patients may stay in hospital only very briefly. Unless review takes place quickly, ward staff who had contact with them may find it difficult to furnish detailed reconstructions of what happened. Although the Inquiry will become more effective in identifying a comprehensive sample, it is likely to experience greater difficulty in obtaining full and reliable details from local clinical review. It surely remains important to encourage early clinical audit based on local data collection in advance of inquest verdicts. In Avon we find that our case register of unexpected deaths is able to cover a population of more than half a million easily, reliably and cost-effectively. The Inquiry would indeed be wise both to promote early clinical review and to seek later confirmation following receipt of inquest verdicts.

As clinicians, we can do much to help the Inquiry. The Health of the Nation initiative gives us the opportunity to show that we really can learn valuable lessons from collaborative clinical experience. I fear that unless we make progress on this, the present sharply focused interest in the search for new approaches to suicide prevention will wane, and not return for many a long year. The Inquiry is indeed now at a crucial stage in its development. Surely it is incumbent upon us all to give it our unreserved support, without which it will never achieve its full potential.

Appleby, L., Shaw, J. \& Amos, T. (1997) National Confidential Inquiry into Suicide and Homicide by People with Mental Illness. British journal of Psychiatry. 170, 101-102.

H. G. Morgan Department of Mental Health, University of Bristol, 4I St Michael's Hill, Bristol BS2 $8 D Z$

\section{Measuring cognitive deterioration in Alzheimer's disease}

Sir: Alzheimer's disease (AD) is characterised by progressive cognitive deterioration. We evaluated event-related potential
(ERP) P300 component latency change over 12 months as a biological marker for progression in 22 patients with probable AD.

Baseline and repeat ERP recordings were obtained from 18 women and four men (mean age 70.8 years, s.d. $=5.6$ years, range 58-79) recruited from the memory clinic at St James's Hospital (Swanwick et al, 1996a). P300 latencies were estimated blind to the dates of the recordings. Deterioration in cognition was assessed using the annual rate of change (ARC) for the Mini-Mental State Examination (MMSE), and CAMCOG.

The baseline mean MMSE score was 19.9 (s.d.=3.9); mean CAMCOG score was 64.0 (s.d.=14.1). The mean ARC in MMSE and CAMCOG scores were 2.6 (s.d.=3.9) and 6.5 (s.d.=9.7), respectively. There was a trend for an increase in the P300 latency (paired $t$-test -1.82 , d.f. $=18, P=0.04$ (onetailed)). There was a significant association between the P300 ARC and both the MMSE and CAMCOG ARCs (Kendall Tau $(\tau)=0.39, P<0.01$ and $\tau=0.35, P=0.02$, respectively). However, the magnitude of change on the cognitive scales was significantly greater than for the P300 latency.

The principal findings are that P300 latency increases with dementia severity, and the rate of increase reflects the rate of cognitive decline. The latter finding is consistent with the previously reported finding that, in patients with 'presenile' $\mathrm{AD}$, the degree of cognitive deterioration generally corresponds with P300 latency changes (St Clair et al, 1988).

In a previously reported study of flash visual evoked potentials on the same patients (Swanwick et al, 1996b) no significant increase in latency was demonstrated. This suggests that ERP recordings may provide a more sensitive index of progression in $\mathrm{AD}$.

In conclusion, this study supports the claim by Ball et al (1989) that P300 latency provides a non-invasive, objective marker of change in cognitive function.

Ball, S. S., Marsh, J.T., Schubarth, G., et ol (1989) Longitudinal P300 latency changes in Alzheimer's disease. Journal of Gerontology. 44. M195-M200.

St Clair, D., Blackburn, I., Blackwood, D., et al (1988) Measuring the course of Alzheimer's disease. A longitudinal study of neuropsychological function and changes in P3 eventrelated potential. British journal of Psychiotry, 152. 48-54.

Swanwick, G. R. J., Coen, R. F., O'Mahony, D., et of (19960) The clinical application of electrophysiological markers in the differential diagnosis of depression and very mild Alzheimer's disease. Journal of Neurology, Neurosurgery \& Psychiotry, 60. 82-86.
_, Rowan, M. J., Coen, R. F., et al (19966) Longitudinal visual evoked potentials in Alzheimer's disease. A preliminary report. Biological Psychiatry, 39, 455-457.

G. R. J. Swanwick 6I Eccles Street, Dublin 7

M. J. Rowan Department of Pharmacology, Trinity College, Dublin

R. F. Coen, B. A. Lawlor, D. Coakley St James's Hospital, Dublin

\section{CYP2D6 genotype and tardive dyskinesia}

Sir: The article by Armstrong et al (1997) on drug-induced movement disorders in schizophrenics in relation to CYP2D6 genotype is important, as research in this area may lead to clues regarding vulnerability to movement disorders such as tardive dyskinesia (TD). The authors conclude that the CYP2D6 genotype may be a factor in determining susceptibility to antipsychotic drug-induced movement disorders including TD. However, this assertion should be treated with caution. Their criteria for diagnosing TD are somewhat arbitrary and, when compared to established criteria such as those by Schooler \& Kane (1982), are liable to diagnose both false positives and false negatives.

We are told that the mutant allele occurs more frequently in the group with chronic movement disorder. This may relate either to TD or to Parkinsonism as both conditions co-existed in the majority of cases. Moreover, this difference between the groups did not reach statistical significance.

The authors have not addressed the issue of masked TD and, in some of their subjects, the movements may have been masked by the neuroleptics. This would have been important to establish in research of this nature.

I feel that the authors should have concluded that the mutant allele predisposed subjects to a chronic movement disorder. Their assertion about TD is premature, not only because of the criteria used, but also because of the mixed clinical picture of their subjects.

Armstrong, M., Daly, A. K., Blennerhasset, R., et ol (1997) Antipsychotic drug-induced movement disorder in schizophrenics in relation to CYP2D6 genotype. British journal of Psychiotry, 170, 23-26.

Schooler, N. C. \&ane, J. M. (1982) Research diagnoses for tardive dyskinesia. Archives of General Psychiatry, 39, 486-487.

S. H. A. Sajjad St Brigid's Hospital, Ballinasloe,

County Galway, Republic of Ireland 